\title{
The Burden of Acting Wise: Sanctioned School Success and Ambivalence about Hard Work at an Elite School in the Netherlands
}

\author{
Jonathan J.B. Mijs $\quad$ Bowen Paulle \\ Harvard University University of Amsterdam
}

This is a pre-print of a paper published in Intercultural Education 27(2): 22-38.

DOI: $\underline{10.1080 / 14675986.2016 .1144383}$

Sam and his classmates despise 'nerds': they say working hard in school makes a student unpopular, and that they purposefully do only the minimum to pass. Research suggests that such 'oppositional' attitudes are prevalent among working class students and/or ethnoracial minorities. Like most of his classmates, however, Sam is white, hails from a privileged background, and attends a selective school in the Netherlands. Deeply ambivalent about working hard and 'acting wise', Sam and the others constituting his adolescent society are thoroughly caught up in peer dynamics which sanction success and promote mediocrity. We link these anti-school peer dynamics to the institutional configuration of education in the Netherlands, characterized by rigid tracking at the end of primary school and non-selective universities: state structures and policies contribute to these privileged students' rationale for 'taking it easy' and doing poorly in school.

Key words: oppositional culture, acting white, acting wise, elite schools, educational tracking, the Netherlands 


\section{INTRODUCTION}

Sam is 14 years old and, in an interview with him, he comes across as strongly opinionated. ${ }^{1}$ He says he despises 'nerds.' Such kids who tend to earn high marks make him feel bad about himself, he states, because he knows he should apply himself and do better at school. However, he is quick to add, he does not feel bad about himself when other students receive high marks - as long as they do not work hard to get them. Sam emphasizes that the quickest way to fall down his school's social ladder is to be 'exposed' as being the kind who studies hard for tests.

Generally speaking, Sam's classmates seem to share his outlook on life in the quasiautonomous institutional domain in which they spend most of their waking hours. More than 80 percent of them believe that receiving high marks contributes to making one unpopular, and a majority of his classmates says being smart reduces their social esteem. Close to 90 percent of Sam's fellow students report that disrupting class and 'driving the teacher crazy' help make you popular in school.

An enormous body of research, which has for decades seeped into popular culture and politics, suggests that such attitudes are prevalent among students classified either as working class, as ethnoracial minorities, or both. However, Sam is putatively 'white' (or native Dutch), and both his parents hold a university degree. ${ }^{2}$ He and his classmates, most of whom would also be considered white and/or native Dutch, attend a highly selective school at the top of the Netherlands' rigidly tracked system of secondary education. Sam's fellow students hail from extremely privileged backgrounds. The overwhelming majority of their parents attended university; eighty-two percent of fathers and no less than 90 percent of mothers.

\footnotetext{
${ }^{1}$ Sam's name and the names of other respondents quoted in this article are pseudonyms.

${ }^{2}$ In the Netherlands, this symbolic category, 'white,' is often used interchangeably with or alongside 'autochthonous,' a construct which in turn is used to signify either 'native Dutch' or 'Western migrant' (Paulle and Kalir 2014).
} 
This paper is an investigation into the context of (upper) middle class and putatively white teenage students' so called 'oppositional' attitudes. To the U.K.- and especially U.S.centric scholarship on class and/or race-based oppositionality or '(cultural) resistance' (Diamond and Huguley 2014; Fryer and Torelli 2010; Hanselman et al. 2014), we bring the case of students attending an elite secondary school in the Netherlands. We draw on qualitative fieldwork at an elite school in the nation's capital, Amsterdam.

For reasons Sam's comments begin to illuminate- but also for reasons having to do with the institutional context that Sam and his classmates take for granted - this article argues the following: at least in the Dutch case and at the secondary school level, it might be better to speak of nearly all teenage students' profound ambivalence regarding hard work, and about the potent sanctioning of, as students put it, 'acting wise' (verstandig doen), than to speak of specifically class and/or race-based 'oppositionality.'

National and comparative international survey research indicates that, across the board, secondary students in the Netherlands are not oriented towards schoolwork. We observe that roughly one third of students across the country report experiencing anti-school sentiments in their peer group (Idema and Jolles 2012a; Mijs 2011; Platform Beta Techniek 2012). Crucially, we also observe that students constructed as ethnoracial minorities and students said to come from working class backgrounds are as likely as putatively white and middle-class students, respectively, to report what are generally, in the social scientific literature, associated with 'oppositional' attitudes (Idema and Jolles 2012b; Mijs 2011). Against this backdrop, the present article contributes to scholarship on 'oppositionality' in education in three ways. First, our case suggests that what is widely associated in the research literature with oppositionality should be re-conceptualized first and foremost as a general phenomenon based on students' immersion in negative peer dynamics. As Coleman (1961) argued half a century ago, these destructive peer dynamics both 
producing and resulting from anti-schoolwork orientations may have little to do with specific class positionings or ethnoracial (di)visions. ${ }^{3}$

Second, our findings suggest that, at least in the upper tier of secondary education in the Netherlands, anti-schoolwork ethics result to an important degree from an institutional configuration providing students with a specific rationale for 'taking it easy.' In our particular case, we suggest, this is due to early tracking into secondary school (age 12/13) and, in nearly all cases, open admission into universities for students who finish the academic ( $v w o$ ) track (age 18/19). ${ }^{4}$

Third, and building on our finding that students tend to be deeply ambiguous about 'acting wise,' we suggest that researchers resist the temptation to build their analysis of negative peer dynamics on seemingly solid, unambiguous cultural blocks. Rejecting this practice at the core of much work on 'oppositionality' we can recall that students are often conflicted about — rather than firmly for or against — hard work yet, all the while, immersed in destructive peer dynamics that more or less force them towards anti-school coping strategies. This final point especially highlights the urgency of what we argue in the conclusion: especially given what we now know about the malleability of adolescents' brains (Steinberg 2014), even in the upper echelons of secondary education where the risks involved are almost certainly less intense than in the most troubled educational contexts, we ignore peer dynamics orienting teens away from sustained and meaningful academic achievement at our peril.

\footnotetext{
${ }^{3}$ We acknowledge the diverging forms and varying degrees that peer sanctions take in different social settings. Our main point here is that the usual social scientific suspects (minority and or working class youth cultures) may be innocent and that there may be more similarities across ('good' and 'bad,' 'middle class' and 'socioeconomically deprived', 'black' and 'white') schools than most would surmise.

${ }^{4}$ To be sure, carefully constructed comparisons across national contexts would be required to demonstrate the existence of a causal relationship. Nevertheless, we hope to demonstrate the plausibility of a link between institutional arrangements and sentiments among students placed onto academic tracks in Dutch secondary schools.
} 


\section{FROM COLEMAN TO 'COMMON SENSE’}

What came to be known as students' 'oppositional' stance toward education has been observed most importantly in three iconic studies: (1) in Coleman's (1961) Adolescent Society, (2) in Willis's (1977) Learning to Labor, dealing with the ultimately self-destructive 'cultural resistance' of working class 'lads' and (3) in Fordham and Ogbu's (1986) article, which is rooted in Ogbu's (1978) seminal work Minority Education and Caste, postulating that hard working and achievement oriented 'involuntary minorities' are 'burdened' by students' perception that they are selling out their fellow racially oppressed group members by 'acting white.'

For our purposes, the key thing to remain mindful of is that Coleman's classic study is the only one of the three that does not associate anti-school attitudes or behavior either with race or class. Most basically, Coleman (1961), who did not rely heavily on terms like 'opposition' or 'resistance,' argued the following: once immersed in their own relatively autonomous status hierarchies and value spheres, teens simply do not like school. Certainly, in such 'worlds apart,' they are not oriented towards consistently working hard on anything associated with the official curriculum. They are strongly oriented, by contrast, towards fast cars, Hollywood blockbusters, sports, good looks, and dating. Yet none of this has anything to do with the subjects schools are, officially, meant to teach.

Coleman's (1961) more subtle point had to do with students understanding all too well that the grades they received depended on the grades of their classmates. It was therefore 'rational' for them, he claimed, to sanction hard work. In an article based on the data used in Adolescent Society, Coleman (Coleman 1959) describes a pervasive 'nonchalance and even a negative attitude towards scholastic matters' among students across wide range of more middle and more working class American high schools. Coleman felt he had an adequate 
sample of American high schools and whether this was due to insufficient data or not, no claims were made about the influence of ethnoracial categories and their alleged cultures.

From the 1970's on, and largely due to Willis' and especially Ogbu's field-redefining efforts, claims and debates about putatively 'resistant' or 'oppositional' attitudes leading to self-destructive school behavior have been based on the negative effects of either working class cultures (resulting from histories of class-based oppression) or ethnoracial minority cultures (rooted in even more brutal histories of ethnoracialized domination)—or both.

Willis's (1977) classic educational ethnography, Learning to Labour, detailed the 'cultural agency' of macho working class 'lads' basically destroying their secondary school in the British Midlands. Willis's lads embodied anti-school practices giving them a sense of superiority in relation to the more conformist youth — the so-called 'ear 'oles' — whom they saw as the natural targets of their mockery and abuse, if they recognized them at all. Operating from within the 'realm of the informal' in which they more or less reigned supreme, Willis argued, the lads deliberately challenged the formal, middle class dominated culture of their school.

In the end, this 'resistance' did not lead to anything like effective opposition of class domination. Rather ironically, as fate would have it, the peer group mediated 'cultural agency' of the working class lads basically ensured that they would do poorly in school and find themselves funneled into blue-collar jobs. Nonetheless, Willis' neo-Marxist analysis seemed to leave the door open for the preverbal next time. Active and willful, Willis implied, the lads' 'resistance' might lead to revolutionary praxis rather than reproduction in the future! The academic conversation about anti-school attitudes and behaviors would never be the same.

Around the same time, Ogbu, a Nigerian-born academic based in the US, became famous for his argument that 'involuntary minorities' tend to hold 'oppositional' collective 
identities which emerged as the racialized legacies of economic, political, social and psychological oppression (Ogbu 1978). From this perspective, collectively stigmatized ethnoracial minorities 'realize and believe' (Fordham and Ogbu 1986, 181) that, regardless of their individual characteristics, they will get substandard educations, face racialized job ceilings, and remain oppressed by members of dominant racial groups. Such minority group members experience 'affective dissonance' when acting out of line with what is culturally expected of them. Students' oppositional stance vis-à-vis 'white' culture and institutional practices is depicted as a collective means of coping rooted in centuries of racial domination. Among students, in Fordham and Ogbu's well-known terms, this process is known as the burden of being perceived to be 'acting white,' or, if you like, of selling out one's group. Expanding on this theme, Fordham and $\operatorname{Ogbu}(1986,183)$ wrote the following:

The perception of schooling as a subtractive process [i.e. as something that comes at the expense of the minority groups' collective welfare] causes subordinate minorities to 'oppose' or 'resist' academic striving, both socially and psychologically. At the social level, peer groups discourage their members from putting forth the time and effort required to do well in school and from adopting the attitudes and standard practices that enhance academic success. They oppose adopting appropriate academic attitudes and behaviors because they are considered 'white.'

Keenly aware that many researchers argue that this burden is either non-existent or far more related to class than race, Ogbu (2003) examined the relatively poor educational outcomes of African American youth in a decidedly (upper) middle class suburb of Cleveland. While arguing that racism contributed to the poor outcomes to some degree, Ogbu concluded that, most fundamentally, the poor outcomes were caused by the culture of the African American students. Despite their (parents') high socio-economic status, that is, these middle class black youth associated excelling in school with 'acting white', Ogbu argued (cf. 
Foley 2004).

If the influence of Willis' class-based analysis has faded, hearted academic debates about Ogbu's race-meets-culture approach to the 'burden' experienced by high-flying students continues to this day (Brüggemann 2014; Diamond and Huguley 2014; Downey, Ainsworth, and Qian 2009; Fryer and Torelli 2010; Gibson 2005; Hanselman et al. 2014; Luciak 2004). Moreover, while many scholars have called into question Fordham and Ogbu's claims and the assumptions underlying them (Carter 2005; Cook and Ludwig 1997; Paulle 2013; Tyson, Darity, and Castellino 2005), in public debate and politics the burden of 'acting white' appears to be an unquestionably, securely established phenomenon that explains - at least to some extent - the achievement gap between minorities and whites (if not, by extension, of lower and middle class students). Accounts of acting white are abundant in newspaper articles and op-eds (Haberman 2006) as well as in popular fiction (Durrow 2010) and non-fiction (McWhorter 2001). The biggest applause line in the then Senator Obama's keynote to the Democratic national convention in 2004- 'children can't achieve unless we .. eradicate the slander that says a black youth with a book is acting white' —is further evidence of Fordham and Ogbu's (in)famous claim being immune from scholarly scrutiny. ${ }^{5}$

Informed by the work fueling this ongoing debate, we explore students' reports about their own attitudes regarding peer dynamics, school work and popularity in Dutch secondary education. The next section describes the institutional structure of secondary education in the Netherlands before moving on to a discussion of the data and data collection process.

\section{EDUCATIONAL INSTITUTIONS IN THE NETHERLANDS}

Dutch secondary education is rigidly differentiated in ability tracks. In the final three

\footnotetext{
${ }^{5}$ See for example Gates Jr.'s New York Times (Aug 1, 2004) piece, "Breaking the Silence."
} 
grades of elementary school (from ages 9 to 12), students take a battery of standardized tests assessing their ability level. Along with the perceptions of their teachers, the results of these exams largely determine students' access to the different tracks of secondary education: vocational (vmbo), higher general (havo) or academic education (vwo). The vocational track takes four years (age 12/13 through 16/17) and grants access to post-secondary vocational education. The higher general track takes five years to complete and provides access to polytechnic tertiary education. The academic track is the only one to grant direct access to university education and takes six years to complete. With the exception most notably of 'pre-med' programs, access to undergraduate university education is non-selective: it is open to all students who hold an academic track degree.

[Table 1 about here]

Some between-track mobility exists. Yet the fact of differentiated curricula levels, concentration of at-risk students in the vocational tracks, and variation in school and teacher quality all work to minimize upward mobility once a student has enrolled in a particular track (Kalmijn and Kraaykamp 2003; Mijs 2008). Initial track placement thus gives a good indication of a student's educational position and perspective. Moreover, studies have shown that 'track placement has a tremendous (and realistic) effect on college expectations and aspirations' (Buchmann and Park 2009; and see Van de Werfhorst and Mijs 2010). Table 1 depicts track placement indicators for the major ethnoracialized groups in the Netherlands, as constructed and recorded by Statistics Netherlands.

Although the situation is different for each ethnoracialized category, from the long dominant perspective of those deploying an ethnoracial lens, a clear pattern is visible: only 38 percent of all putatively 'white' students attend vocational education ( $v m b o)$, whereas a much 
larger number of students said to be of Moroccan (64 percent), Turkish (66 percent) and Afro-Caribbean descent (56 percent) is enrolled in vocational education. Conversely, the percentage of students that could qualify for a university education is 32 for ostensibly white students, and 20, 13 and 13, respectively, for students understood to be of Afro-Caribbean, Turkish and Moroccan descent who, in popular discourse, are said to contribute to the formation of 'black' schools' (zwarte scholen).

There are clear indications that educational outcomes in the Netherlands should not be seen, first and foremost, through an ethnicizing lens. It has long been known that children of poorly educated parents classified as non-Western migrant minorities tend to do better in terms of educational outcomes than do children of equally poorly educated 'autochthonous' parents who are said to contribute to the formation of white schools (Hustinx and Meijnen 2001). When comparing so called (second generation) non-Western ethnic minorities and putatively white autochtones — but again taking some steps to control for socio-economic status - another important study demonstrated that if there is any ethnoracialized 'group' of students in the Netherlands being 'penalized' for their cultural background, it is the one constituted above all be 'natives.' Van De Werfhorst and Van Tubergen $(2007,432,434)$ sum up this finding as follows:

'[E]thnic minorities attend lower levels of education and score lower on achievement tests. These ethnic differences, however, are attributable to social class background... [T] aking into account the lower parental education and occupational class, ethnic differences in achievement vanish, and differences in secondary school type almost disappear. What remains of the differences in educational level is not an ethnic penalty, but an ethnic advantage: Turks, Moroccans, Surinamese and Antilleans choose higher 
types of secondary schooling than natives with comparable class

backgrounds.'

\section{DATA}

The data for this study were collected by the lead author throughout the 2010/2011 school year and especially during a period of intensive fieldwork at a secondary school in Amsterdam. This school occupies a position at the top of the tracked system of secondary education in the Netherlands. Out of 62 secondary schools in Amsterdam, it is one of only six that offer exclusively academic track education. Its students are among the three percent of students country-wide who are enrolled in a school that exclusively offers academic track education. Like virtually all schools in the Netherlands, this school is publicly-funded and parents' financial contributions to school are voluntary.

The data are drawn from interviews with teachers and students. Direct observations were carried out in classrooms as well as in extra-classroom settings. In order to help systematize the observations, a vignette survey $(\mathrm{N}=68)$ was conducted as were follow-up interviews in five group sessions. At the outset of such sessions, students were offered a survey including vignettes and background questions. After having observed the students' interactions while filling out the survey, the strategy was to initiate a class discussion about the topic of popularity and achievement to which students were introduced by the vignettes. In total, 31 boys and 37 girls were interviewed in groups of 13 students on average. Three groups of students were in ninth grade (derde klas; aged 14-15), two were in their seventh grade (eerste klas; aged 12-13). Students' evaluations of these vignettes and their background characteristics are reported in Appendix A1. 


\section{FINDINGS: LESSONS FROM AN ELITE SCHOOL}

Meeting with students in one-hour sessions in groups of 10-15, the aim was to capture students' (mix of) attitudes as well as to gain insight into regularities of classroom dynamics and more or less stable overall status hierarchies. The sessions began with a short survey to be completed by students, individually, in 5 to 10 minutes time. The surveys introduced the students to the topic of popularity in school. As such it served to get everyone focused on the matter at hand. Sooner or later, the survey questions triggered discussion. In nearly every meeting, the one or two line vignettes used to introduce a set of qualities or themes led to push-back from a number of students.

For instance, one vignette described Delia along the following lines: 'Very pretty. People say she's prettier even than her sister who is a model.' Students were then asked to write down whether she would be popular or not popular in their school. Regularly, students insisted that there was no way for them to decide on such a delicate matter based on a simplistic characterization. In such cases, students were encouraged to write down precisely these types of concerns. Others would try to boycott the survey by scribbling pejoratives; e.g., stating that they would 'pimp' the pretty girl (Peter, ninth grade). Many simply did as instructed.

The remaining time in these sessions was used for discussions on popularity, asking students to explain what they thought of various characterizations. What defined popularity and how was popularity related to achievement? The discussions were enriching. They allowed students to spew their criticism of the survey. And in spewing, they would reveal what they did and did not look for in their peers; what makes and what breaks popularity as they understood it.

As mentioned in the opening of this paper, Sam's depiction of the 'nerd' as despicable 
resonated with many other students in these class discussions. Laura, another ninth grader, for instance, said a student who refuses to do homework would typically be considered 'tough' and 'cool'-although she was quick to add that she herself did not see things this way. Some students expressed a sense of solidarity with others who did not do their homework. When asked, many of them said they would express anger toward a fellow student if (s)he were to apply themselves too vehemently. Indeed the students reported that if they were to be quizzed unexpectedly, and if one student were to earn a high mark, they would consider this a breach of trust. Such a turn of events would reveal that someone had been doing more work than was required. Linda (seventh grade) explains: 'The other week there was this girl. She goes all quiet when she gets her paper back. So my friend, he walks over to her desk and snatches it from her hands. And you know what? She got a perfect score! And she told the whole class she hadn't studied for it. Well, we showed her.'

Students expressed antipathy, more generally, towards students who were said to always do their homework, to actively participate in class and to receive high marks. All of this was associated, at once, with being nerdy and, as Linda said, with 'showing off that they are better than you.' Such behavior, students considered to be evidence of 'acting wise' (verstandig doen) — a curious and complex amalgam of being uncool/nerdy and literally behaving in wise ways (rather than stupidly or impulsively), acting superior to other students, and making others feel bad about themselves.

Interestingly, and in contrast to the negative responses elicited when consistently working hard was thematized, many students spoke positively of fictional Felipe, described in the vignette as follows: 'Felipe is a very smart kid. He does not work hard for it, but holds good grades-especially in mathematics and chemistry.' Whereas some would describe Felipe as a 'nerd' and, as such, 'probably not very popular' (Laura, ninth grade), a majority of students described him in favorable terms commenting on how smart he must be, admiring 
his 'brains,' or even saying things like 'Felipe is the man' (Dirk, ninth grade). Indeed when asked which of the seven vignette characters students would most like to hang out with, Felipe was often named. As our conversations evolved it became clear why. Students felt pressured by the demands school placed on their time, having to be at school for long hours, and having to do homework after school. This they considered to be a major strain on their social lives. Consider Deborah (seventh grade): 'I think it's important to get a passing grade, but there's more on my mind than that: I play sports and I want time to hang out with my friends.' Peter (ninth grade): 'There are weeks that I don’t do any homework. I love it. Sometimes you have to do something, but I try to keep it to a minimum. You know, it's boring.' As such, they liked the idea that such a Felipe character might be able to assist them with their homework because, having to make a minimal effort at his own work, he would be left with a lot of time to hang out. In short, Felipe's coolness (despite his high marks) had to do with his easy going work ethic and the possibility that he might help lighten their workloads.

While being smart could help make one popular under the right conditions, as the students indicated, it was nevertheless trumped by three qualities highlighted in the vignettes: (1) having rich parents, (2) being physically attractive, and (3) acting out in class. The most popular person overall was Alma, the fictional 'rich girl' although boys favored (beautiful) Delia. In third place came Celso who was described in the vignette as follows: 'Celso often acts out in class. Teachers often don't know how to deal with him.'

Students noted that 'standing out' is an important part of popularity in school, and many agreed that the best way for a guy to stand out was with humor, and in showcasing one's verbal agility. Consider the following two comments in a class discussion: 'I love a guy who makes me laugh' (Naomi, seventh grade); 'School can be so boring. I really enjoy it when someone gets on the teacher's nerves' (Mick, ninth grade). For girls, in many cases, to 
stand out was first and foremost to be considered pretty by their classmates. When questions were asked about this, Lisa (ninth grade) sighed at the level of naivety that was on display. It was utterly obvious that Delia, the pretty girl, was popular: 'Duh!'

The survey conducted among students $(\mathrm{N}=68)$ at the beginning of class helps with the quantification of the students' beliefs or, at least, their situated utterances about them (Table 2). Eighty-two percent of students agreed that, generally, holding high marks contributed to making a student unpopular. Eighty-nine percent of students reported thinking that outspokenness and disruptive behavior in class contributed to popularity. The survey shows that the one thing students agreed on as contributing to popularity most was wealth: ninety-seven percent of students thought that being rich aided in the quest to be popular. In second place came physical attractiveness: ninety-four percent of students thought good looks helped make students popular (Figure 1).

[Figure 1 about here]

[Table 2 about here]

\section{CULTIVATING MEDIOCRITY OR ‘ACTING WISE’}

Treading deeper into the currents and counter-currents of sentiments about popularity and academic performance, two perspectives were observable. One perspective, adhered to by a small number of students, was that it was 'plain stupid not to care about school' (Iris, ninth grade). Moreover, it was reasoned, not caring about school would not bring you popularity because, ultimately, 'it will get you kicked out of school' (Irene, seventh grade). This perspective was voiced most frequently among students in their first year (who may have been more afraid than older students of being demoted to lower tracks). The other 
perspective raised was that there is little reason to care about school for it bears no consequences as long as one does enough to pass. This perspective might be labeled cultivating mediocrity (Tyson, Darity, and Castellino 2005) or flirting with failure. By contrast, from the teenage students' points of view, this might be seen as a strategy for immunizing oneself form the tedium of school work while maintaining enough time to "have a life.' Either way, doing more than the minimum was almost universally associated with 'showing off' and 'acting wise.'

The main theme here is that students who consistently applied themselves made others feel bad about themselves. In short, 'acting wise' confronted the majority of students with their own ambivalence about living up to their parents' and teachers' expectations, on the one hand, and living up to student norms (and having enough time to hang out as well as be popular) on the other. It remained unclear whether, as Coleman claimed, the antipathy towards high achieving students was based on concerns that competition would lead to greater pressure to work hard. But the students' mix of positive and negative associations with hard work and strong achievement was hard to miss.

The pro-school side of the ambiguous worldview on display here is easy to comprehend. It corresponds with a broader societal emphasis on the importance of doing well in school and the meritocratic promise that educational degrees hold for success in adulthood (Mijs 2015). Given the backgrounds of these students and their placement on the fast track to the university, the anti-school or at least anti-hard work sentiment might be considered more difficult to understand. On the other hand, what could be more intuitive than adolescents' drive to belong to the 'in crowd'? What could make more sense to teens than pursuing the immediate gratification of 'hanging out' rather than working hard to create opportunities for 'the future'- a concept which research suggests is little more than a vague abstraction for many during this phase of life? Breakthroughs in developmental neuropsychology indicate 
that even deep into puberty, boys in particular are markedly less able than adults (or even children in pre-adolescent phases) to accurately assess risk, consider future outcomes, and ignore the opinions of peers (Crone 2009).

On top of this, the particularities of the students' institutional setting likely reinforced their anti-work ethic. As alluded to above, Dutch secondary education is highly selective 'at the gate,' i.e. at the start of secondary school (age 12/13) when students are tracked in rigidly differentiated ability levels (Van de Werfhorst and Mijs 2010). Universities in the Netherlands however provide access to anyone who completes the academic track in secondary school, regardless of how well or poorly one does in school. While there is a slow movement toward more selective access to university programs, as recently as 2008, ninetyseven percent of entering students were granted non-selective entry. The institutional reality of tracked secondary education in the Netherlands is that out of a hundred students who enter the academic track, roughly 93 will graduate and 86 will eventually enroll in university (Netherlands Ministry of Education 2008). Conversely, no student in vocational education is allowed direct entry to university education. These students placed on lower tracks may try to gain access indirectly, through enrollment in academic track education after completion of the vocational track, or through enrollment in polytechnic tertiary education and working their way up to university. Yet on average only around 22 out of a 100 vocational students successfully complete this roundabout route (Van Elk, Van der Steeg, and Webbink 2009). Even if those we study do not do this, as social scientists we have to (1) connect the worldviews of our subjects to their objective probabilities and (2) relate their perceptions to broader state structures and polices. Objectively, from age $12 \mathrm{on}$, the educational destinies of these mostly (upper) middle class and putatively 'white' students on an elite academic track are pretty much set because of the institutional arrangements brought into being and systemically enforced by the Dutch government. In other words, these students' utterances 
related to popularity and working hard, once on their elite track, must be seen as the foreground, easily observable, manifestations of something less immediately observable yet vitally important: implicitly, these students took their destinations for granted and doing this is borne out by objective graduation and university enrollment statistics. Something they took completely for granted because they had no counter examples that would make it 'visible'namely the institutional structuring of their educational field — promoted doing just enough to pass and pressuring peers to do the same. Certainly, there was no major institutional pressure working against the cultivation of mediocrity; nor were there strong institutionalized incentives to work hard and excel. The fact that the fish did not see the water, one might say, is all the more reason for us to emphasize its significance.

While broadly speaking our findings run counter to the claims associated most obviously with Ogbu and Willis, ${ }^{6}$ this brings us to an irony that might be said to highlight a similarity with these two scholars' approaches. Fordham and Ogbu's (1986) Capital Hill students did not believe hard work would pay off for those stigmatized by their 'collective identity' in schools or economic fields oriented towards 'white culture.' Willis $(1977,129)$ argued that his lads felt the same way because, from their vantage points, the working class appeared destined to remain on the 'bottom of the gradient no matter how its atoms move.' Similarly, we can now add, academic track students in the Netherlands saw no reason to exert themselves. They too strolled and stumbled along towards what they perceived to be their fixed destination. Whereas the outlooks for these privileged teens were extremely positiveat least compared to Fordham and Ogbu's African-American students at Capital Hill and Willis' working class lads of the British Midlands - the effect of their implicitly institutionalized perspectives rooted in objective inequalities and life chances is highly analogous: these students were opposed to putting in the extra effort that was required for

\footnotetext{
${ }^{6}$ That is, notwithstanding differences in form, degree and consequences, the peer dynamics that undermine school norms, described here, constitute a general phenomenon in secondary education, not limited to the 'opposition' associated with working class and/or ethnoracial minority kids.
} 
excelling in school because, they felt, there was so little at stake. In short, in their cases of atrisk youth (of color) with bleak futures and in our case of elite students with 'bright futures,' harmful peer pressures seem to have been based on more or less realistic perceptions that no one had much for which to strive.

While our findings tend to align most clearly with Coleman's, a subtle difference in our adolescent society and his may be worth mentioning. Coleman's students in the US pressured each other not to work hard because they were made to feel that they were in competition with each other. Admission to more selective colleges in the US is based in part on grade point averages and rankings within one's graduating class. Compared to the field of higher education in the Netherlands, the space of higher education in the US is deeply divided and highly hierarchical. As students in the Netherlands graduating from the academic track are granted access to all the universities and to nearly all the various university programs in the Netherlands, they objectively had far less reason to see themselves as being locked in a competition with each other. Students who acted 'wise' made these students feel bad about themselves for the reasons mentioned above. But students who acted wise were not seen as threats to the degree described in Coleman's classic study.

As Tyson et al.'s (2005) work emphasizing social structural realities implies, our main finding about the effects of institutional logics is this: the 'burden' placed on the shoulders of elite Dutch students who were said to be 'acting wise' cannot be understood outside of formal bureaucratic arrangements, far outside the adolescents' control. In other words, the Dutch students' ambiguous mix of feelings and beliefs about academic excellence and popularity correspond to these students' undeniably realistic perspectives on the life chances and institutional realities they faced. There is evidence that similar institutional forces may influence students in the Netherlands and in the U.S. in similar ways even though they are placed at the opposite, and far more damaging end of the same tracking spectrum (Paulle 
2013: 128-29).

\section{CONCLUSION: HIGHLY PRIVILEGED AND TRAPPED IN NEGATIVE PEER} DYNAMICS

In a nutshell, we find no reason to assume any ethnoracial or social class dimensions to 'oppositionality' in Dutch secondary education: the sentiments we describe in this paper seem to reflect the peer dynamics that confront a majority of students, not just a minority from disadvantaged socioeconomic or ethnoracial backgrounds. We do however find strong support for the sociological vision of life in 'adolescent societies' advanced long ago by Coleman (1961). Coleman's main claim is that high schools are anti-intellectual places because adolescents simply do not care about school. Because of the values and status hierarchies that take hold in such settings, in his view, negative peer dynamics in secondary schools threaten to cut teenage students off from adult-dominated, future-oriented worlds of learning based on formal curricula. Our findings also align with Tyson et al.’s (2005) important work which both (1) offers findings running counter to what Fordham and Ogbu's 'burden of acting white' thesis would lead one to expect and (2) emphasizes that social structural and institutional characteristics may help explain when sanctions are placed on students said to be acting pro-hard work and pro-achievement, in ways that may appear, on the ground, as the fixed 'cultural' attributes of certain socio-economic or ethnoracialized categories.

While at times quite positive about 'acting wise' and doing well in school, for reasons this article has detailed, none of the students constituting the elite school examined here were anywhere near powerful enough to free themselves from the chains of anti-school rituals and anti-intellectual status games into which they were thrust. Counter-intuitive or not, that is, we 
discovered adolescents attending a top tier school in the Netherlands who indicated that they were basically trapped in negative peer dynamics. As we demonstrated, these peer dynamics relate both to internal micro-interactional and underlying institutional forces. From below and above, forces influenced these students that none of them were powerful enough to transform no matter what they may have believed.

Suggesting that teenage pupils in the Netherlands generally, and highly privileged Dutch secondary school students specifically, are 'trapped' in negative peer dynamics outside their control may sound alarmist. Certainly, there is no reason to assume that the educational experiences of these privileged students 'taking,' as the sexist old saying goes, the 'gentleman's C' are anywhere nearly as harmful as those of adolescents forced into high poverty, high stress schools of urban exile (cf. Paulle 2013). In fact, we have reason to expect that the expression of attitudes and peer dynamics, in particular the form and degree of peer sanctioning of pro-school behavior, will vary from one social context to the next, in part as a condition of the institutional configuration of the school or educational system more broadly that students find themselves in. The negative peer dynamics discussed in this paper are almost certainly less intense and less damaging that what can all too often be found in high poverty, non-selective secondary schools - in the Netherlands and elsewhere. Yet the dangers laid bare in the previous pages should not be underestimated.

The Duke of Wellington may have been exaggerating when, upon visiting the playing-fields of Eton, he made his now famous remark ("It is here that the battle of Waterloo was won!”). Yet informal socialization, character formation, and soft skill development processes in elite adolescent worlds apart deserves our focused attention (cf. Khan 2010). Many of the students placed on pre-university tracks in the Netherlands will go on to occupy positions of power in various fields of Dutch society. To these insights about (informal) socialization, schooling, and the formation of elites we must add the following. We have 
known for some time that adolescents are 'hard wired' to be impulsive. We know that in the heat of the moment teens do things they themselves consider 'dumb,' during their calmer moments, in part because they are notoriously incapable of assessing longer-term risks. Perhaps all of us can recall the viscerally felt urgency of belonging at very least in the middle of our adolescent society's pecking order.

It is therefore not at all dramatic, exaggerated, or alarmist to suggest that teensincluding those born into socio-economic and ethno-racial privilege if not academically 'set for life,' are in many cases ensnarled in negative peer dynamics. During an especially formative period of their lives, adolescents are forced, by custom if not by law, to attend secondary schools. When secondary schools fail to regulate anti-intellectual and anti-work peer dynamics, they end up doing more than merely fostering relatively poor educational outcomes. As our research indicates, (even) at the top of the field of secondary education in the Netherlands - and in ways that James Coleman could not have imagined half a century ago - this should be seen as effectively thrusting teenagers into socially significant spheres of life that can negatively impact their social and cognitive development. 


\section{REFERENCES}

Brüggemann, Christian. 2014. "Romani Culture and Academic Success: Arguments against the Belief in a Contradiction." Intercultural Education 25 (6): 439-52. doi:10.1080/14675986.2014.990229.

Buchmann, Claudia, and Hyunjoon Park. 2009. "Stratification and the Formation of Expectations in Highly Differentiated Educational Systems.” Research in Social Stratification and Mobility 27 (4): 245-67.

Carter, Prudence L. 2005. Keepin' It Real: School Success Beyond Black and White. New York: Oxford University Press.

Coleman, James S. 1959. "Academic Achievement and the Structure of Competition." Harvard Educational Review 29: 330-51.

- 1961. The Adolescent Society: The Social Life of the Teenager and Its Impact on Education. Westport, CT: Greenwood Press.

Cook, Philip J., and Jens Ludwig. 1997. "Weighing the "Burden of "Acting White": Are There Race Differences in Attitudes Toward Education?.” Journal of Policy Analysis and Management 16: 256-78.

Crone, Eveline A. 2009. "Executive Functions in Adolescence: Inferences From Brain and Behavior." Developmental Science 12: 825-30.

Diamond, John B., and James P. Huguley. 2014. "Testing the Oppositional Culture Explanation in Desegregated Schools: The Impact of Racial Differences in Academic Orientations on School Performance." Social Forces 93 (2): 747-77. doi:10.1093/sf/sou093. 
Downey, Douglas B., James W. Ainsworth, and Zhenchao Qian. 2009. "Rethinking the Attitude-Achievement Paradox Among Blacks.” Sociology of Education 82 (1): 1-19. doi:10.1177/003804070908200101.

Durrow, Heidi W. 2010. The Girl Who Fell From The Sky. Chapel Hill, NC: Algonquin.

Foley, Douglas. 2004. “Ogbu's Theory of Academic Disengagement: Its Evolution and Its Critics.” Intercultural Education 15 (4): 385-97. doi:10.1080/1467598042000313412.

Fordham, Signithia, and John U. Ogbu. 1986. “Black Students' School Success: Coping with the 'burden of "acting White."”" The Urban Review 18 (3): 176-206. doi:10.1007/BF01112192.

Fryer, Roland G. Jr, and Paul Torelli. 2010. “An Empirical Analysis of 'Acting White.”” Journal of Public Economics 94: 380-96.

Gibson, Margaret A. 2005. "Promoting Academic Engagement among Minority Youth: Implications from John Ogbu's Shaker Heights Ethnography.” International Journal of Qualitative Studies in Education 18 (5): 581-603. doi:10.1080/09518390500224853.

Haberman, Clyde. 2006. "Helping Turn Dreamers Into Doctors Helping Turn Dreamers Into Doctors." The New York Times, November 17, sec. NY Region Opinions.

Hanselman, Paul, Sarah K. Bruch, Adam Gamoran, and Geoffrey D. Borman. 2014. "Threat in Context School Moderation of the Impact of Social Identity Threat on Racial/Ethnic Achievement Gaps.”Sociology of Education 87 (2): 106-24. doi:10.1177/0038040714525970.

Hustinx, P, and P Meijnen. 2001. “Allochtone Leerlingen in Het Voorgezet Onderwijs: De Rol van Enkele Gezinsfactoren Nader Geanalyseerd [Allochtonous Students in Secondary Education: A Reanalysis of the Role of Certain Familial Factors].” In 
Succesvolle Allochtone Leerlingen [Successful Allochtonous Students], edited by W

Meijnen, J. C. C. Rupp, and T. Veld, 47-71. Apeldoorn: Garant.

Idema, Wietske, and Jelle Jolles. 2012a. “Gymnasium Eerste Klas... Van Slimmeriken En Bange Brugpiepers [From Brains to Scaredy-Cats].” Didactief, no. March: 30-31.

_. 2012b. "Kunnen En Mogen Leerlingen Excelleren? [Can and Should Students Excel?].” Bij de Les, 6-9.

Kalmijn, M., and G. Kraaykamp. 2003. "Dropout and Downward Mobility in the Educational Career: An Event-History Anaylsis of Ethnic Schooling Differences in the Netherlands." Educational Research and Evaluation 9 (3): 265-87.

Khan, Shamus Rahman. 2010. Privilege: The Making of an Adolescent Elite at St. Paul's School. Princeton, NJ: Princeton University Press.

Luciak, Mikael. 2004. "Minority Status and schooling-John U. Ogbu's Theory and the Schooling of Ethnic Minorities in Europe.” Intercultural Education 15 (4): 359-68. doi:10.1080/1467598042000313395.

McWhorter, John. 2001. Losing the Race: Self-Sabotage in Black America. New York: Schuster.

Mijs, Jonathan J.B. 2008. "Meritocracy or Plutocracy? Finding Explanations for the Educational Disadvantages of Moroccan Immigrants Living in the Netherlands." Amsterdam Social Science 1 (1): 44-70.

_. 2011. "A Burden of "Acting "Wise"': Ambivalence Towards Academic Achievement in Dutch Education." Paper presented at Eastern Sociological Society Annual Conference, Philadelphia, PA.

_ 2015. "The Unfulfillable Promise of Meritocracy: Three Lessons and Their Implications for Justice in Education.” Social Justice Research, (in press). doi:10.1007/s11211-014-0228-0. 
Netherlands Ministry of Education. 2008. "Bestel in Beeld [The Educational System]." The Hague: The Netherlands Ministry of Education, Culture and Science.

Ogbu, John U. 1978. Minority Education and Caste: The American System in Cross-Cultural Perspective. San Diego, CA: Academic Press.

—.2003. Black American Students in An Affluent Suburb: A Study of Academic

Disengagement. Mahwah, NJ: Lawrence Erlbaum.

Paulle, Bowen. 2013. Toxic Schools: High-Poverty Education in New York and Amsterdam.

Chicago, IL: University of Chicago Press.

Paulle, Bowen, and Barak Kalir. 2014. "The Integration Matrix Reloaded: From Ethnic Fixations to Established Versus Outsiders Dynamics in the Netherlands." Journal of Ethnic and Migration Studies 40 (9): 1354-74. doi:10.1080/1369183X.2013.847783.

Platform Beta Techniek. 2012. "The Excellence Model. Young People on Excellence.” The Hague: Platform Beta Techniek.

Steinberg, Laurence. 2014. Age of Opportunity: Lessons from the New Science of Adolescence. Boston, MA: Houghton Mifflin Harcourt.

Tyson, Karolyn, William Darity, and Domini R. Castellino. 2005. 'It's Not 'a Black Thing': Understanding the Burden of Acting White and Other Dilemmas of High Achievement.” American Sociological Review 70 (4): 582-605. doi:10.1177/000312240507000403.

Van de Werfhorst, Herman G., and Jonathan J.B. Mijs. 2010. “Achievement Inequality and the Institutional Structure of Educational Systems: A Comparative Perspective." Annual Review of Sociology 36: 407-28.

Van De Werfhorst, Herman G., and F. Van Tubergen. 2007. "Ethnicity, Schooling, and Merit in the Netherlands." Ethnicities 7 (3): 416-44. 
Van Elk, Roel, Mark Van der Steeg, and Dinand Webbink. 2009. "The Effect of Early

Tracking on Participation in Higher Education.” CPB Document 182. The Hague:

CPB Economic Policy Analysis.

Willis, Paul E. 1977. Learning to Labor: How Working Class Kids Get Working Class Jobs. New York: Columbia University Press. 
TABLES \& FIGURES

Table 1. School track enrollment by ethnoracial category (in percentage)

\begin{tabular}{lcccc}
\hline Ethnoracial category & Vmbo & Havo & Vwo & Total \\
Native/white & 38 & 30 & 32 & 100 \\
Moroccan & 64 & 23 & 13 & 100 \\
Turkish & 66 & 21 & 13 & 100 \\
Afro-Caribbean & 56 & 24 & 20 & 100 \\
\hline
\end{tabular}

Source: Statistics Netherlands 2012/13

Table 2. Popularity in school by gender (in percentage)

\begin{tabular}{l|l|lc|lc|cc}
\hline \multirow{2}{*}{ Trait } & & Boys & & Girls & & \multicolumn{2}{|l}{ Total } \\
Wealth & Almatte & Popular & Unpopular & Popular & Unpopular & Popular & Unpopular \\
\hline Good grades & Berna & 95.0 & 5.0 & 100 & 0.0 & 97.4 & 2.6 \\
Acting out & Celso & 93.4 & 84.6 & 20.0 & 80.0 & 17.9 & 82.1 \\
Beauty & Delia & 96.4 & 3.6 & 95.0 & 15.0 & 88.6 & 11.4 \\
Not caring & Elias & 58.3 & 41.7 & 50.0 & 50.0 & 53.8 & 46.2 \\
Smarts & Felipe & 64.3 & 35.7 & 30.8 & 69.2 & 48.1 & 51.9 \\
\hline
\end{tabular}

Source: Author's Amsterdam Elite School Survey. 
Figure 1. Popular traits in school.

\title{
Popular traits in school
}

\author{
口Popular $\quad$ Unpopular
}

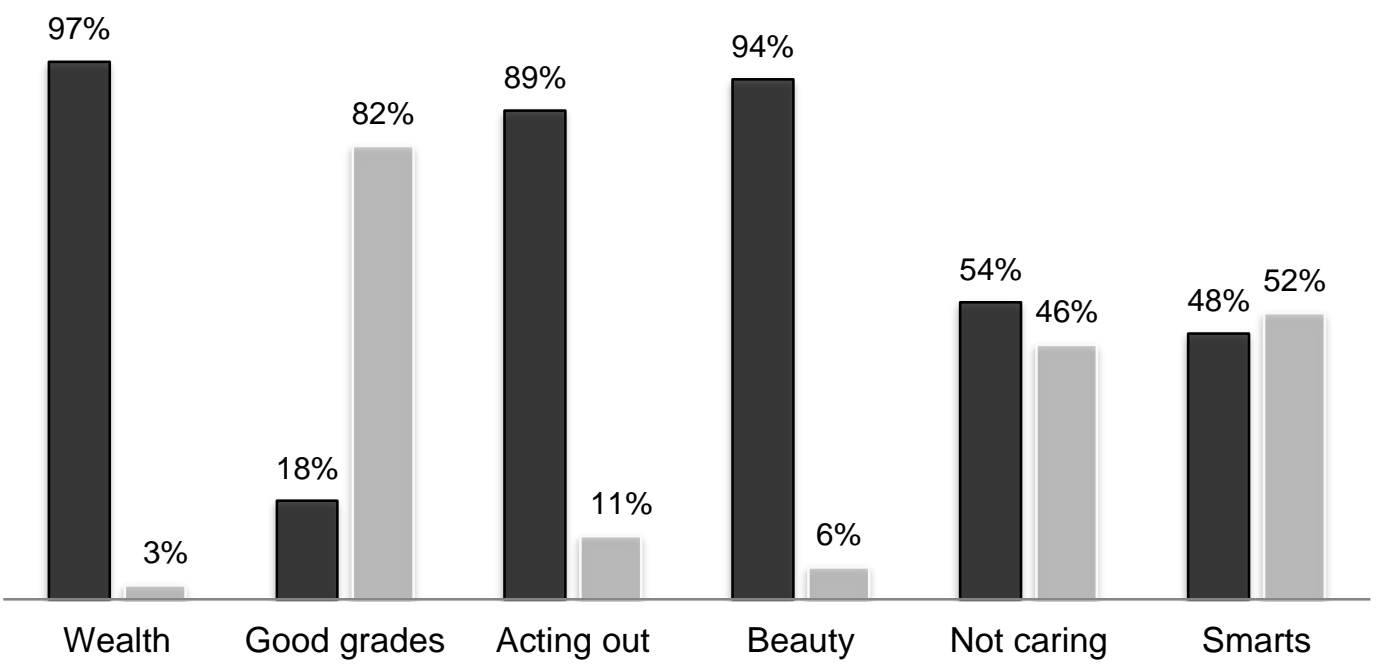

Note. The numbers indicate the percentage of students that does or does not believe the trait to contribute to popularity in school. Source: Author's Amsterdam Elite School Survey. 


\section{ACKNOWLEDGEMENTS}

The lead author is grateful to Orlando Patterson, Jocelyn Viterna, Mary Waters, and William Julius Wilson for their support and their extensive comments on earlier drafts of this manuscript. I am appreciative too for helpful input from participants in seminars at the University of Amsterdam, Harvard University, the 2012 Aage Sorenson Memorial Conference at Stockholms Universiteit, Sweden, and the 2011 Eastern Sociological Society Annual Conference. We thank the editor and three anonymous reviewers of this journal for their thoughtful feedback. 
Table A1. Description of vignettes and control variables from Amsterdam Elite School Survey $(\mathrm{N}=68)$

\begin{tabular}{lcc}
\hline Variables & Metric & Mean \\
\hline Alma has wealthy parents. She spent her birthday in [fancy hotel] & with her best friends. \\
Wealth is popular/unsure/unpopular & Binary & $97.4 \% / 2.6 \%$
\end{tabular}

Berna holds the highest marks in class. Perhaps of the whole school even.

Good grades is popular/unsure/unpopular Binary $\quad 17.9 \% / 82.1 \%$

Celso often acts out in class. Teachers often don't know how to deal with him.

Acting out is popular/unsure/unpopular Binary $\quad 88.6 \% / 11.4 \%$

Delia is very pretty. People say she's prettier even than her sister who is a model.

Beauty is popular/unsure/unpopular Binary 94.2\% / 5.8\%

Elias does not care about academics. Homework and school marks do not interest him.

Not caring is popular/unsure/unpopular Binary $\quad 53.8 \% / 46.2 \%$

Felipe is a very smart kid. He does not work hard for it, but holds good grades-especially in mathematics and chemistry.

Smarts is popular/unsure/unpopular

Binary

Binary

$48.1 \% / 51.9 \%$

Student's gender (male)

Nominal

$45.6 \%$

Student's school year (first)

Nominal

Native/ 'white'

Non-western immigrant descent

$17.6 \%$

Born in Amsterdam

Nominal

$85.1 \%$

Primary school teacher's advice

Nominal

Mixed track

$10.5 \%$

Academic track

$89.6 \%$

Grades for Dutch Language

Continuous

7.07

0.81

Grades for Mathematics

Continuous

6.54

0.91

Grades for English

Continuous

6.96

0.91

Composite GPA

Continuous

6.85

Father attended university (yes)

Binary

0.67

Mother attended university (yes)

Binary

$81.8 \%$

Books at home

Ordinal

A shelf

Few shelves

One book case

More than one book cases

Believes it is important to pursue a university Nominal

$88.2 \%$ degree (yes) 